\title{
Antioxidant Potential, Phytochemicals Composition, and Metal Contents of Datura alba
}

\author{
Waliullah Khan $\mathbb{D}^{1},{ }^{1}$ Sidra Subhan, ${ }^{1}$ Dilawar Farhan Shams, ${ }^{2}$ Sahib Gul Afridi, ${ }^{3}$ \\ Riaz Ullah $\left(\mathbb{1},{ }^{4}\right.$ Abdelaaty A. Shahat $\left(\mathbb{1},{ }^{4,5,6}\right.$ and Ali S. Alqahtani $(\mathbb{1})$ \\ ${ }^{1}$ Department of Chemistry, Abdul Wali Khan University, Mardan, Pakistan \\ ${ }^{2}$ Department of Environmental Sciences, Abdul Wali Khan University, Mardan, Pakistan \\ ${ }^{3}$ Department of Biochemistry, Abdul Wali Khan University, Mardan, Pakistan \\ ${ }^{4}$ Medicinal, Aromatic and Poisonous Plants Research Center (MAPRC), College of Pharmacy, King Saud University, \\ P.O. Box 2457, Riyadh 11451, Saudi Arabia \\ ${ }^{5}$ Phytochemistry Department, National Research Centre, P.O. Box 1262233, El Bohouth St., Dokki, Giza, Egypt \\ ${ }^{6}$ Department of Pharmacognosy, College of Pharmacy, King Saud University, P.O. Box 2457, Riyadh 11451, Saudi Arabia
}

Correspondence should be addressed to Waliullah Khan; drwali@awkum.edu.pk and Riaz Ullah; rullah@ksu.edu.sa

Received 19 March 2019; Accepted 28 May 2019; Published 17 June 2019

Academic Editor: Dr Muhammad Hassham Hassan Bin Asad

Copyright (c) 2019 Waliullah Khan et al. This is an open access article distributed under the Creative Commons Attribution License, which permits unrestricted use, distribution, and reproduction in any medium, provided the original work is properly cited.

\begin{abstract}
This study investigated the phytochemical characteristics and antioxidant activity in leaves, roots, stem, flower, and seed parts of Datura alba (D. alba). The study also assessed the heavy metal ( $\mathrm{Cr}, \mathrm{Mn}, \mathrm{Zn}$, and $\mathrm{Cu}$ ) accumulation in each part of the plant. Among the phytochemicals, alkaloids were found only in leaves while tannins, flavonoids, and phenols were present in all parts of the plant. For antioxidant activity, free radical scavenging assay for 2,2-diphenyl-1-picrylhydrazyl (DPPH) was performed using ascorbic acid as the standard. Higher activity was shown by stem extract in methanol and leaf extract in n-hexane, ethyl acetate, and chloroform. Furthermore, all the target heavy metals were detected in all plant sections with the highest concentration of $\mathrm{Zn}$ in leaves and $\mathrm{Cu}$ in stem, root, flower, and seed. Due to stronger antioxidant potential and phytochemical composition, D. alba could prove as valuable prospect in pharmaceutical formulations by taking part in the antioxidant defense system against generation of free radicals.
\end{abstract}

\section{Introduction}

A great number of modern medicines have been derived from plants that are considered as important sources of medicinal agents to treat different diseases [1]. For drug development, bioactive compounds like flavonoids, tannins, phenols, and alkaloids in medicinal plants play a vital role [2]. Datura is a shrub-like perennial herb containing 15 species, of which D. alba is considered as the most important drug plant for its chemical and ornamental properties. It belongs to the family Solanaceae and is commonly known as Devil's trumpet or Angel's trumpet with an average height of $1.5 \mathrm{~m}$ [3]. This plant is widely used in medicines to treat diseases like cough, asthma, diarrhea, epilepsy, insanity, rheumatic pains, catarrh, hysteria, and skin ulcers [4]. D. alba is also a heavy-metaltolerant plant that can grow easily in metal polluted sites. Its hyperaccumulative nature has been exploited for the recovery of toxic heavy metals from contaminated ground water $[5]$.

For normal cellular activities, a balance between the antioxidant defense mechanism and the produced reactive oxygen species (ROS) is very important. An increase in ROS disturbs this equilibrium and results in oxidative stress [6]. Although ROS, which are produced from partial reduction of oxygen during high metabolism, are important for life, repeated stress conditions lead to increase in energy utilization and hence production of more ROS, which may harm cells, tissues, and organs. Several plant extracts possess significant antioxidant activities to treat many diseases and disorders such as liver toxicity, diabetes hepatotoxicity, and other complications [7].

Phytochemicals derived from plants are nonnutritional natural compounds that are important for numerous body functions in humans. Many of these compounds found 
in food products are known to have antioxidant potential due to the occurrence of $\mathrm{OH}$ group [8]. The antioxidants prohibit the oxidative damage to various macromolecules like nucleic acids, proteins, and lipids and scavenge free radicals generated from biochemical reactions [9]. A reaction of these free radicals with macromolecules has been reported to stimulate apoptosis that may cause various physiological, cardiovascular, and neurological disorders [10]. Various types of phytochemicals such as phenolic acids, ascorbic acid, tocopherols, and bioflavonoids having antioxidant characteristics have been used to treat many diseases [11].

Keeping in view the importance of D. alba in traditional medicines and the existence of bioactive compounds in various parts of this plant, this study was intended to investigate its phytochemical and pharmacological properties. Earlier studies have mainly used hydroalcoholic and ethanol extracts for phytochemical and antioxidant analysis of D. alba $[12,13]$. This study investigated the crude phytochemicals (qualitative and quantitative), antioxidant activities, and heavy metals in D. alba using different types of solvents (polar and nonpolar). Also, the study was aimed at boosting the scientific database on the subject medicinal herb.

\section{Materials and Methods}

2.1. Preparation of Crude Extracts. The plant samples were collected from District Charsadda, Khyber Pakhtunkhwa, Pakistan. The plant specimen was identified at the Department of Botany, Abdul Wali Khan University Mardan, Pakistan, following the flora of Pakistan. The plant was assigned voucher number AWKUM.Bot.168.10.9:44-45 and was placed at the Department of Botany's herbarium. The plant extracts were made following the standard procedures [14-16].

2.2. Determination of Phytochemicals. Powdered samples $(5 \mathrm{~g})$ were added in $100 \mathrm{~mL}$ of distilled water and kept for two days at room temperature for complete extraction. After two days, the extracts were filtered through Whatman filter paper (Grade 41). Qualitative and quantitative phytochemicals analyses for each sample were performed using the methods available in literature [17-20].

2.2.1. Alkaloids Test. For alkaloid test, $\mathrm{HCl}(1 \%)$ was added to $3 \mathrm{~mL}$ of aqueous extract and then heated on water bath at $100^{\circ} \mathrm{C}$. The extract was then cooled and a few drops of Mayer reagent were added. The sample was kept for $5 \mathrm{~min}$ and observed for turbidity, which indicated the presence of alkaloids [21].

2.2.2. Flavonoids Test. For flavonoids test, $10 \%$ lead acetate solution $(1 \mathrm{~mL})$ was added to $1 \mathrm{~mL}$ of each extract. The solution was allowed for few minutes until yellow precipitate was formed [22].

2.2.3. Tannins Test. For tannins test, 1 to 2 drops of ferric chloride $\left(\mathrm{FeCl}_{3}\right)$ solution and $1 \mathrm{~mL}$ of distilled water were added to $1 \mathrm{~mL}$ of the extract. The extract solution was thoroughly mixed and left for few minutes until formation of a blue or green black coloration $[23,24]$.
2.2.4. Phenols Test. For phenols test, $2 \mathrm{~mL}$ of ethanol and few drops of $\mathrm{FeCl}_{3}$ solution were mixed in the extract solution and allowed for few minutes. The change in color to black indicated the presence of phenols $[23,24]$.

\subsection{Quantitative Analysis of Phytochemicals}

2.3.1. Alkaloids Content. For alkaloids content, $100 \mathrm{~mL}$ of acetic acid (10\%) in ethanol was first mixed with $5 \mathrm{~g}$ of dry plant sample and then covered and allowed for $4 \mathrm{hrs}$ to complete the extraction process. This was followed by filtration and then concentrating the filtrate using a water bath to $1 / 4$ th of the initial volume. Concentrated ammonium hydroxide $\left(\mathrm{NH}_{4} \mathrm{OH}\right)$ was then added until the formation of precipitate, which was then filtered, washed several times with diluted $\mathrm{NH}_{4} \mathrm{OH}$, and dried to obtain the alkaloid residue.

2.3.2. Flavonoids. Flavonoids in various parts of $D$. alba were analyzed using the method described by Natic et al. [25].

2.3.3. Tannins. The total content of tannins was determined following the method by Medini et al. [26] with little modifications. To $50 \mathrm{~mL}$ of distilled water, $500 \mathrm{mg}$ of plant sample was added and stirred for $1 \mathrm{hr}$. Afterwards, the solution was filtered and made up to $50 \mathrm{~mL}$. Then $2 \mathrm{~mL}$ of $0.1 \mathrm{M} \mathrm{FeCl}{ }_{3}$ solution was added to $5 \mathrm{~mL}$ of the filtered sample into a test tube and the absorbance was measured within 10min at $395 \mathrm{~nm}$ using UV-5100B UV/VIS spectrophotometer.

2.3.4. Phenols. Total phenolic content was determined quantitatively following Oyewole and Akingbala [27]. The powdered plant sample $(3 \mathrm{~g})$ was boiled with $30 \mathrm{~mL}$ of ether in a condenser for $15 \mathrm{~min}$ at $34^{\circ} \mathrm{C}$ and then filtered to obtain the ether extract. To $50 \mathrm{~mL}$ volumetric flask, $5 \mathrm{~mL}$ of extracted sample, $5 \mathrm{~mL}$ of concentrated isoamyl alcohol, and $2 \mathrm{~mL}$ of $\mathrm{NH}_{4} \mathrm{OH}$ solution were added and the final volume was made up to $50 \mathrm{~mL}$ with distilled water. The solution was left for 30 min until the color change. Finally, the absorbance was measured at 505nm using UV/VIS spectrophotometer.

\subsection{Total Antioxidant Capacity Assessment. The DPPH} method was used to assess the total antioxidant capacity by measuring the DPPH assay according to Rivero-Perez [28]. $\mathrm{DPPH}$ is a commercially available nitrogen free radical with dark purple color showing maximum absorbance at $517 \mathrm{~nm}$. When antioxidant molecules (methanol extracts) were incubated at room temperature with DPPH, the DPPH radical reduced with the transfer of hydrogen from antioxidant molecule, resulting in color change from dark purple to yellow and the absorbance of DPPH decreased. The DPPH scavenging activity was determined for various extracts of $\mathrm{n}$-hexane, ethyl acetate, methanol, and chloroform. Ascorbic acid and methanol were used as standard and blank solvent, respectively. Stock solutions $(25 \mathrm{mg} / \mathrm{mL})$ were prepared in methanol from each extract. Working solutions (10, 20, 30, 40 , and $50 \mu \mathrm{g} / \mathrm{mL}$ ) were prepared from these stock solutions. DPPH solution $(0.96 \mathrm{mM})$ was also prepared in the same solvent. Thereafter, $1 \mathrm{~mL}$ of DPPH solution was mixed with each working solution followed by incubation for $30 \mathrm{~min}$ at room 


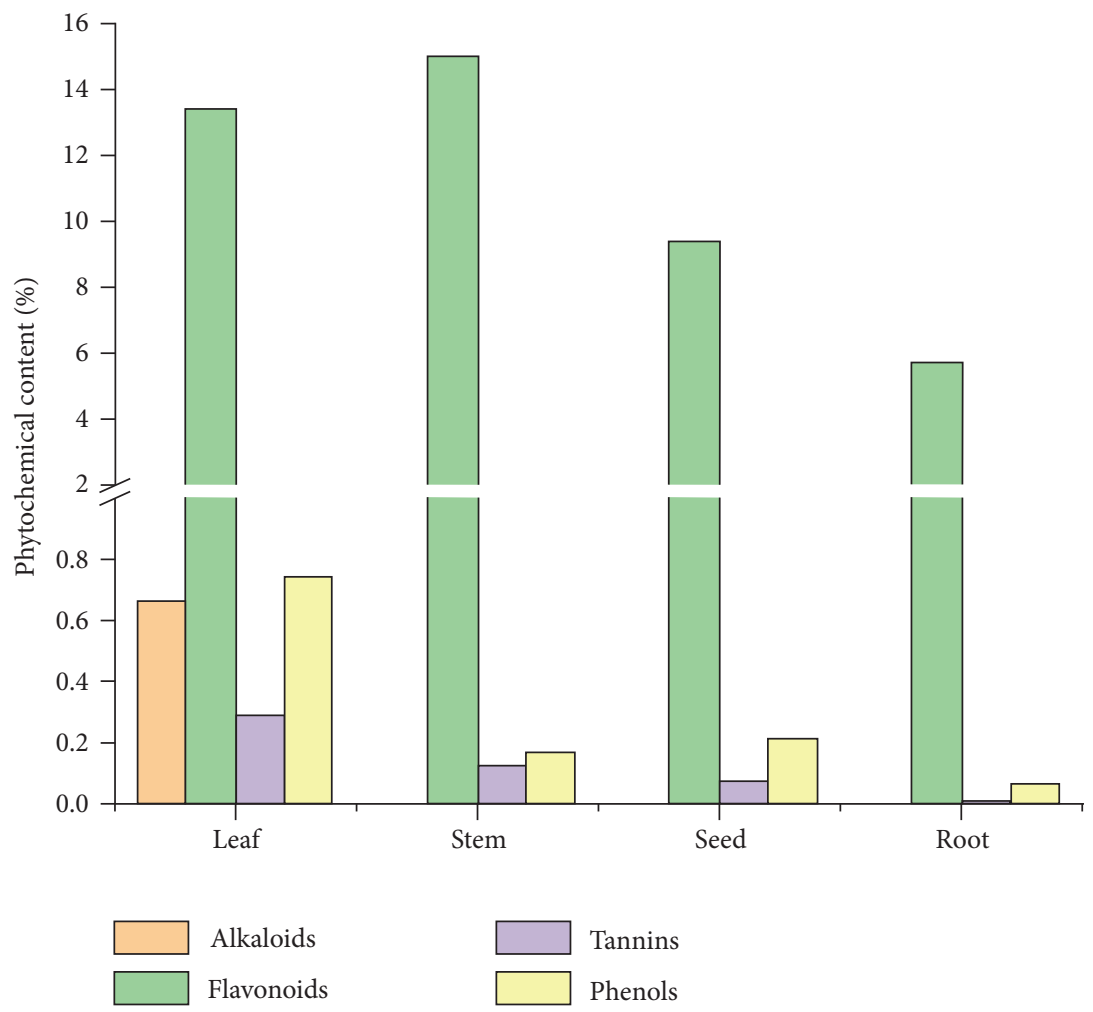

FIgURE 1: Phytochemicals content in different parts of D. alba.

temperature. Control was prepared by adding $1 \mathrm{~mL}$ DPPH to $4 \mathrm{~mL}$ methanol. The absorbance of samples and the control was measured at $517 \mathrm{~nm}$ using UV/VIS spectrophotometer. The DPPH scavenging activities were measured as percent inhibition using the following equation:

$$
\begin{aligned}
& \text { Inhibition (\%) } \\
& =\left[\frac{\text { Absorbance }(\text { Control })-\text { Absorbance (test sample) }}{\text { Absorbance (Control) }}\right] \\
& \quad \times 100
\end{aligned}
$$

The $\mathrm{IC}_{50}$ value of sample was obtained by linear regression analysis of concentrations and inhibition (\%).

\subsection{Determination of Heavy Metals}

2.5.1. Digestion of Plant Parts. Analytical grade concentrated per chloric acid $\left(\mathrm{HClO}_{4}\right)$ and nitric acid $\left(\mathrm{HNO}_{3}\right)$ were used for the digestion. Samples $(0.2 \mathrm{~g})$ of dry grounded plant parts (root, stem, leaves, seeds, and flowers) were weighed into $100 \mathrm{~mL}$ beakers. Predigestion of the samples was performed with $\mathrm{HNO}_{3}(5 \mathrm{~mL})$, followed by cooling and digestion again to $\mathrm{HClO}_{4}$ fumes [29]. After digestion, distilled water $(50 \mathrm{~mL})$ was added and the mixture was nearly boiled to achieve complete dissolution. After cooling, the samples were filtered using Whatman filter paper (Grade 41).

2.5.2. Heavy Metal Analysis. Heavy metals analyses for zinc $(\mathrm{Zn})$, copper $(\mathrm{Cu})$, manganese $(\mathrm{Mn})$, and chromium $(\mathrm{Cr})$ were performed in triplicates for all parts of medicinal plants using atomic absorption spectrophotometer (Analyst 700, Perkin Elmer).

\section{Results}

3.1. Phytochemical Analysis. The phytochemical analysis of D. alba showed the presence of alkaloids, flavonoids, tannins, and phenols. Qualitative analysis of phytochemicals in various plant extracts showed the presence of flavonoids, tannins, and phenols in all the four parts (leaf, stem, seed, and root), while alkaloids were found only in leaf (Table 1). This was in line with the literature as the maximum amounts of alkaloids and bioactive compounds are present in leaves [30]. Quantitative analysis of phytochemicals is shown in Figure 1.

3.2. Determination of Antioxidant Activity. The DPPH scavenging activity of the various parts of $D$. alba extracts in different solvents at concentrations varying from 10 to $50 \mu \mathrm{g} / \mathrm{mL}$ was determined with Vit. C (ascorbic acid) as standard. Figure 2 indicates the inhibition (\%) as a function of Vit. C concentration. The results revealed that, with the increasing Vit. C concentration, the percentage inhibition (\%) increased at a rate of $0.361 \% \pm 0.119$ per $\mu \mathrm{g} / \mathrm{mL}$ of Vit. C, while the maximum activity was attained at $50 \mu \mathrm{g} / \mathrm{mL}$.

3.2.1. Antioxidant Activity of Methanol Extracts. Free radical scavenging assay was used to determine the antioxidant activity of methanol extracts of root, stem, leaf, and seed parts 
TABLE 1: Qualitative analysis of phytochemicals.

\begin{tabular}{lcccc}
\hline Sample & Alkaloids & Flavonoids & Tannins & Phenols \\
\hline Leaf & ++ & ++ & ++ & ++ \\
Stem & -- & ++ & ++ & ++ \\
Seed & -- & ++ & ++ & ++ \\
Root & -- & ++ & ++ \\
\hline
\end{tabular}

++ : present; - -: absent.

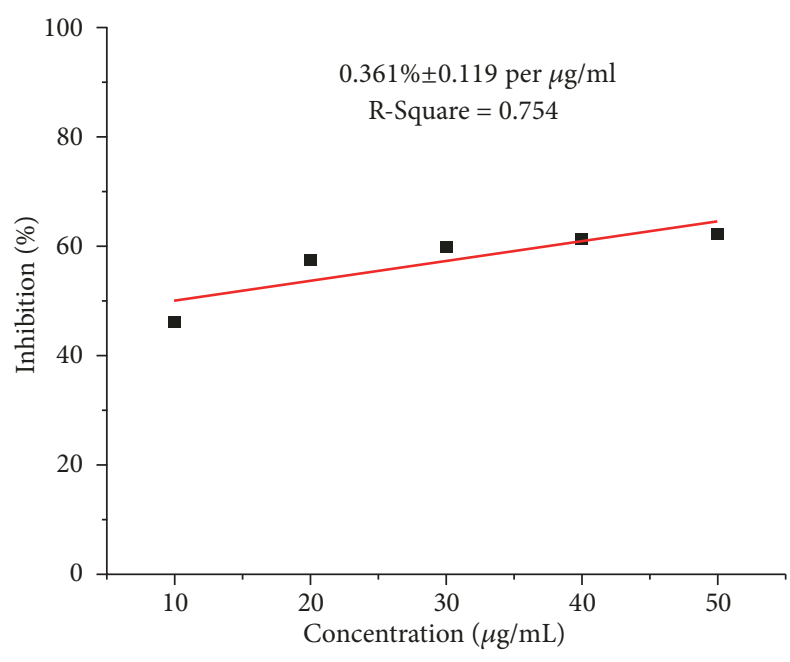

FIGURE 2: Antioxidant activity of ascorbic acid.

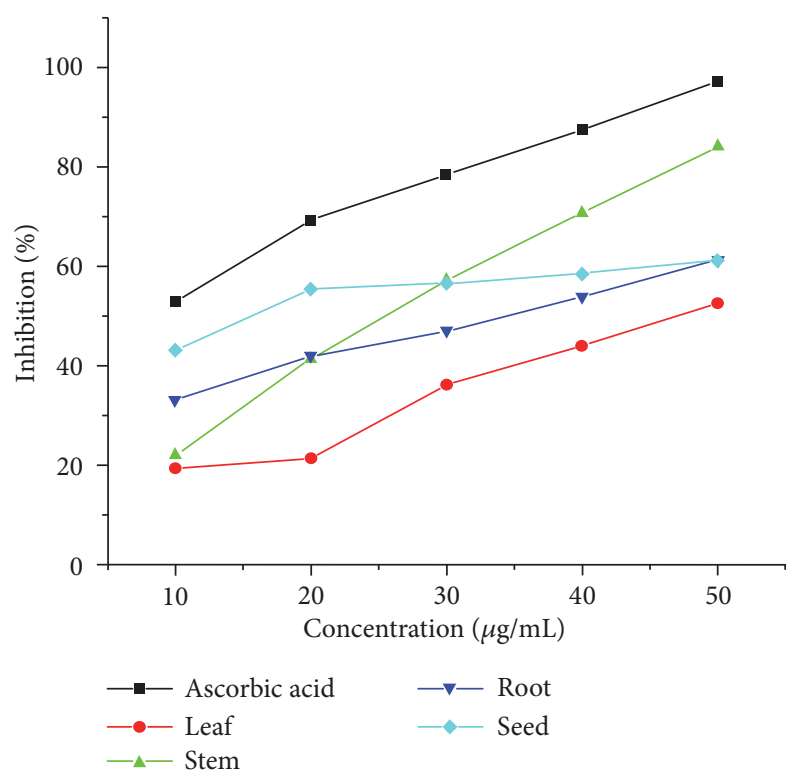

FIGURE 3: Antioxidant activity of methanol extracts.

of D. alba (Figure 3). A concentration range of $10-50 \mu \mathrm{g} / \mathrm{mL}$ was used. According to results, the standard ascorbic acid showed the maximum antioxidant activity at all concentrations $(10-50 \mu \mathrm{g} / \mathrm{mL})$ in comparison to the stem, root, leaf, and seed extracts. The percent inhibition of stem extract was $57.19 \%, 70.78 \%$, and $84.05 \%$ at a concentration of 30,40 , and

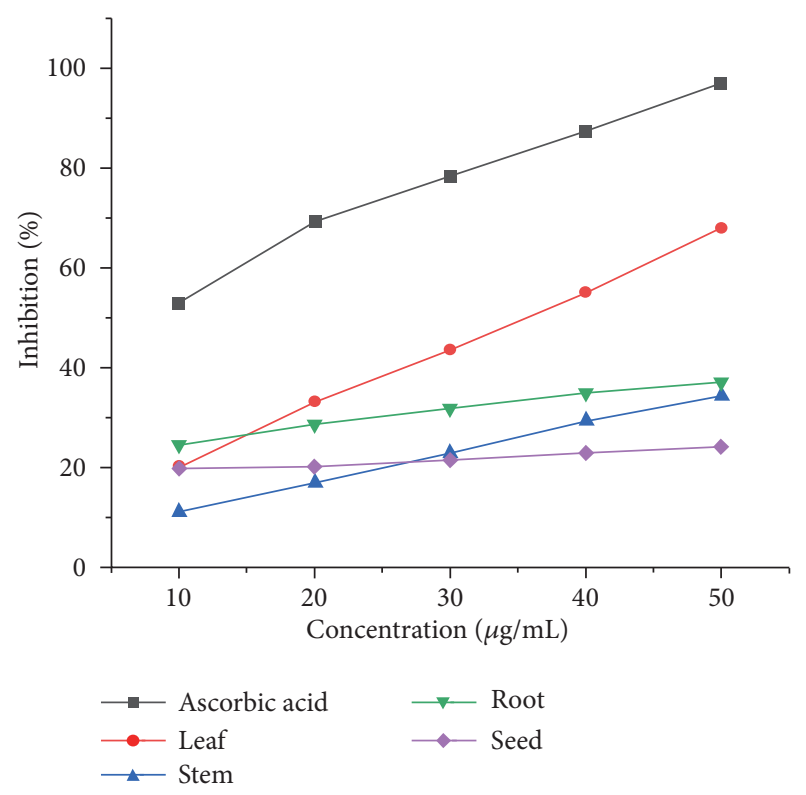

Figure 4: Antioxidant activity of n-hexane extracts.

$50 \mu \mathrm{g} / \mathrm{mL}$, respectively. Seed extracts showed higher activity at lower concentration; root extracts exhibited moderate activity, while leaf extracts showed low activity.

3.2.2. Antioxidant Activity of n-Hexane Extracts. As shown in Figure 4, the n-hexane extracts of all parts of $D$. alba showed antioxidant activity that decreased in the following order: leaf $(68 \%)>\operatorname{root}(37 \%)>\operatorname{stem}(34 \%)>$ seed $(24 \%)$ by the DPPH free radical scavenging method.

3.2.3. Antioxidant Activity of Ethyl Acetate Extracts. Antioxidant activities for various parts of $D$. alba in ethyl acetate are shown in Figure 5. From the $\mathrm{IC}_{50}$ values, it is evident that extract of seeds had the lowest inhibition activity, whereas that of leaf possessed the highest inhibition activity. The antioxidant activity for the ethyl acetate extracts decreased in the order of leaf $>$ root $>$ stem $>$ seed.

3.2.4. Antioxidant Activity of Chloroform Extracts. In chloroform extracts, root extract had high antioxidant activity at $40 \mu \mathrm{g} / \mathrm{mL}$ and $50 \mu \mathrm{g} / \mathrm{mL}$ and leaf at $30 \mu \mathrm{g} / \mathrm{mL}$ (Figure 6). Similarly, the stem also showed high activity at low concentration of $10 \mu \mathrm{g} / \mathrm{mL}$ but moderate activity at all other tested concentrations. As a whole, the root section showed high 
TABLE 2: Heavy metal concentration (ppm) in various parts of $D$. alba (Mean $\pm \mathrm{SD})$.

\begin{tabular}{lcccc}
\hline Sample & $\mathrm{Cu}$ & $\mathrm{Cr}$ & $\mathrm{Zn}$ & $\mathrm{Mn}$ \\
\hline Leaf & $2.83 \pm 0.95$ & $0.98 \pm 0.05$ & $5.98 \pm 0.03$ & $0.74 \pm 0.01$ \\
Stem & $2.48 \pm 0.15$ & $1.31 \pm 0.37$ & $1.51 \pm 0.02$ & $0.18 \pm 0.01$ \\
Flower & $4.23 \pm 0.25$ & $1.30 \pm 0.30$ & $1.93 \pm 0.04$ & $0.19 \pm 0.01$ \\
Root & $2.83 \pm 0.15$ & $2.06 \pm 0.05$ & $0.85 \pm 0.01$ & $0.25 \pm 0.01$ \\
Seed & $3.51 \pm 2.45$ & $1.42 \pm 0.06$ & $1.89 \pm 0.35$ & $0.10 \pm 0.00$ \\
\hline
\end{tabular}

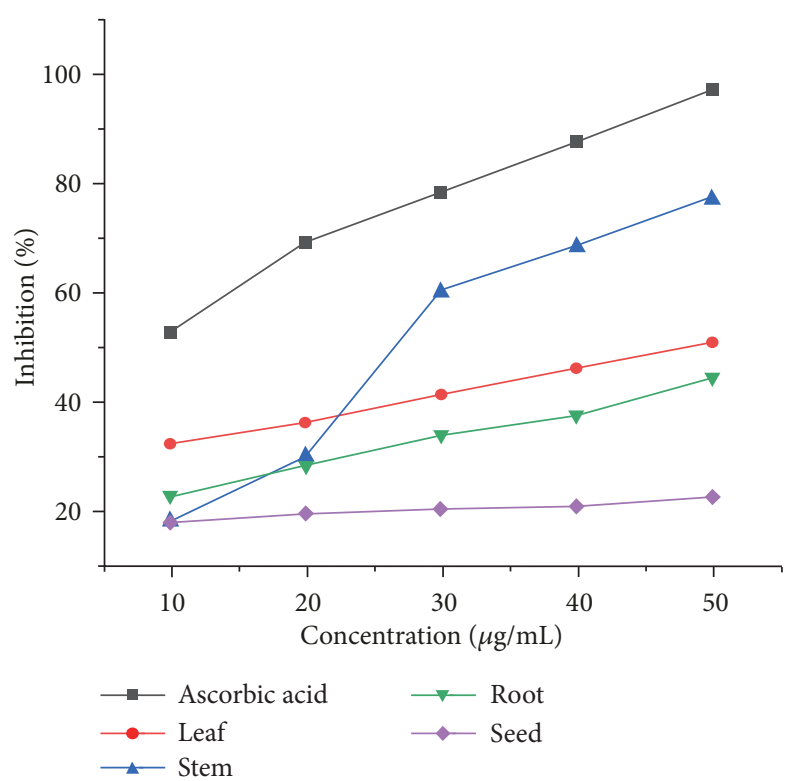

FIGURE 5: Antioxidant activity of ethyl acetate extracts.

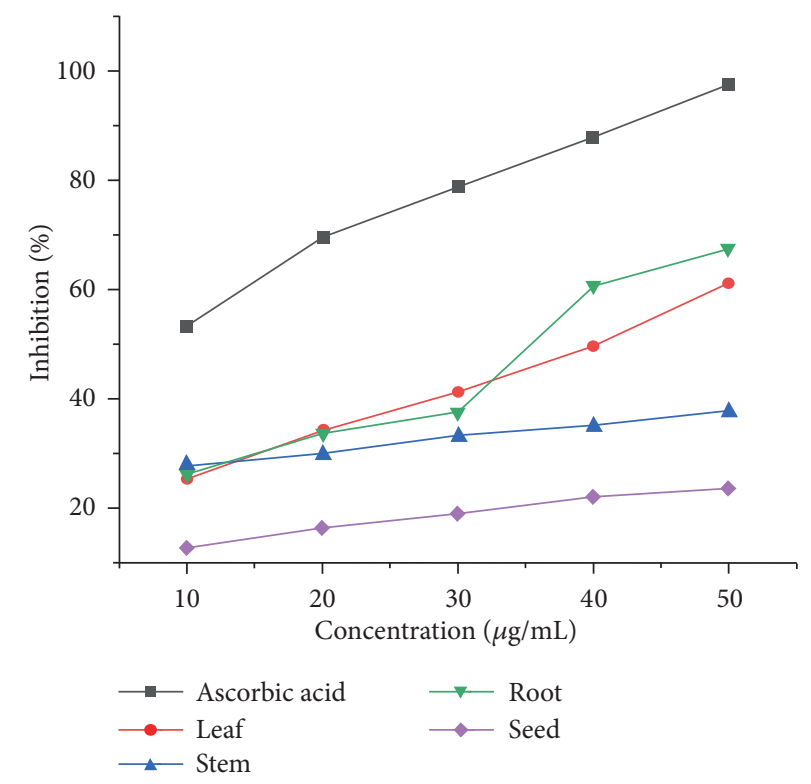

FIgURE 6: Antioxidant activities of chloroform extracts. antioxidant activity at higher concentrations and the leaf at lower concentrations.

3.2.5. Antiradical Activity on $\mathrm{DPPH}\left(\mathrm{IC}_{50}\right) . \mathrm{IC}_{50}$ is the concentration at which the inhibition is $50 \%$. It has an inverse relationship to antioxidant activity. The decreasing order of antiradical activity was Vit. C > methanol > chloroform $>$ n-hexane $>$ ethyl acetate. Figure 7 shows the $\mathrm{IC}_{50}$ values for various extracts in various parts of the plant in the following order: leaf $<$ root $<$ seed $<$ stem.

3.3. Determination of Heavy Metals. Heavy metal analysis in various parts of the plant revealed that the leaf part contained high concentration of $\mathrm{Zn}$, while $\mathrm{Cu}$ was found in comparatively higher concentration in all parts of the plant (Table 2). Mn was present in the lowest amounts among the target heavy metals. High concentration of $\mathrm{Cu}$ was found in flower of $D$. alba $(4.23 \pm 0.25 \mathrm{ppm})$ followed by seed $(3.51 \pm 2.45 \mathrm{ppm})$, leaf $(2.83 \pm 0.95 \mathrm{ppm})$, root $(2.83 \pm 0.15 \mathrm{ppm})$, and stem $(2.48 \pm 0.15 \mathrm{ppm})$, respectively (Table 2$)$. Maximum concentration of $\mathrm{Mn}$ was found in the leaf $(0.74 \pm 0.01 \mathrm{ppm})$ followed by root $(0.25 \pm 0.01 \mathrm{ppm})$, flower $(0.19 \pm 0.01 \mathrm{ppm})$, stem $(0.18 \pm 0.01 \mathrm{ppm})$, and seed $(0.10 \pm 0.00 \mathrm{ppm})$. These results were within the limits of WHO. In case of $\mathrm{Cr}$, root has a concentration of $2.06 \pm 0.05 \mathrm{ppm}$, seed $1.42 \pm 0.06 \mathrm{ppm}$, stem
$1.31 \pm 0.37 \mathrm{ppm}$, flower $1.30 \pm 0.30 \mathrm{ppm}$, and leaf $0.98 \pm 0.07 \mathrm{ppm}$. Highest levels of $\mathrm{Cr}$ were found in root and the lowest in leaves.

\section{Discussion}

4.1. Phytochemical Analysis. The overall concentration of flavonoids in all parts of the plant was more than phenols and tannins and this corresponded with the findings by Genskowsky et al. [31]. Alkaloids are a special group of secondary nitrogenous compounds. Plants containing alkaloids were used during the middle ages for various human and animal diseases [32]. Most of the plants contain flavonoids that constitute a large number of polyphenolic compounds. They are a key component of human dietary intake that could be used in curing cardiovascular dysfunctions, cancer, and inflammatory diseases [33].

Tannins are polyphenolic compounds with higher molecular weight which are present in many plants and are known to provide protection against microorganisms. In animals, tannins may cause indigestion of proteins and ultimately retardation of animal growth due to formation of hydrogen bonds with carboxylic groups [34]. Meanwhile, phenolic compounds consist of aromatic ring (with the phenyl hydroxyl or its substituted radicals), which are plant 


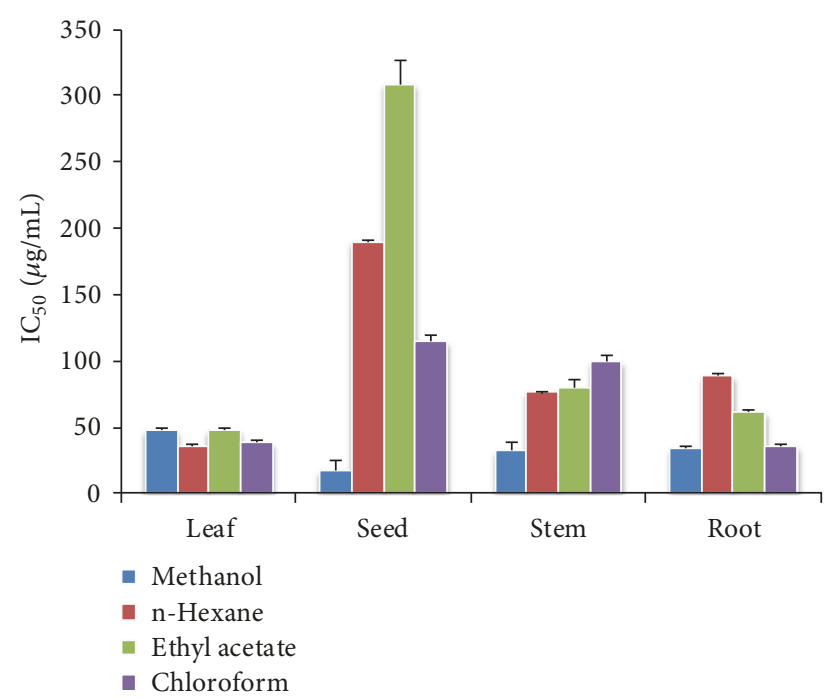

Figure 7: The $\mathrm{IC}_{50}$ values for leaf, seed, stem, and root extracts in methanol, n-hexane, ethyl acetate, and chloroform.

secondary metabolites having little contribution towards the physiological or ecological functions of the plant [35].

4.2. Determination of Antioxidant Activity. Plants are the main source of natural antioxidants as many of the phytochemicals have antioxidant properties due to hydroxyl groups in their structural formulae. Their main activity is to protect the defense system against oxidative stress by free radicals [36]. Various antioxidant compounds produced by plants stabilize ROS [37]. ROS are of two types, free radicals such as hydroxyl and superoxide anion radicals $\left(\mathrm{O}_{2}{ }^{-}\right)$and nonfree radicals, mostly activated oxygen like singlet oxygen $\left({ }^{1} \mathrm{O}_{2}\right)$ and $\mathrm{H}_{2} \mathrm{O}_{2}$. DPPH that has free radical scavenging activity was used in this assay. It is reduced by the transfer of hydrogen atom from antioxidant molecule resulting in the color change at specific wavelength.

The maximum absorbance for methanol extracts was obtained at $50 \mu \mathrm{g} / \mathrm{mL}$ for leaves, stem, root, and seed extracts, respectively. According to these results, stem extract exhibited the maximum antioxidant activity due to the presence of higher quantity of flavonoids (15\%) as shown in Figure 1 [38]. Due to high flavonoid and phenolic content, the nhexane extracts of leaves have relatively better reducing power and DPPH radical scavenging activity. It was also rich in flavonoids (13.4\%) and phenolic content ( $0.742 \%)$, which is responsible for its comparatively higher antioxidant activity. The same for the ethyl acetate extracts decreased in the order of leaf $>$ root $>$ stem $>$ seed. These results for chloroform extracts revealed the medicinal importance of the plant with all parts containing good amounts of flavonoids that are a source of antioxidant activity. It is also evident from the $\mathrm{IC}_{50}$ values that all parts of $D$. alba exhibited antioxidant activity.

4.3. Antiradical Activity on DPPH $\left(I C_{50}\right)$. Plant extracts that have higher concentration of flavonoids have better capability to donate hydrogen atoms to the scavenging free radicals. This decreasing order of antioxidant activity showed that a lesser quantity of the extract having higher radical activity is needed to inhibit $50 \%$ of DPPH free radical, whereas a larger quantity is required for the lesser active extract. It is clear from Figure 6 that all the plant extracts were active species for antioxidant activity due to the existence of flavonoids, which can neutralize the free radicals to give stable compounds.

4.4. Determination of Heavy Metals. According to FAO/ WHO [39], the permissible limit for $\mathrm{Zn}, \mathrm{Cu}, \mathrm{Cr}$, and $\mathrm{Mn}$ is $27.4,3.00,0.02$, and $2 \mathrm{ppm}$, respectively. From the results, $\mathrm{Zn}$ concentration was within the standard limits. $\mathrm{Zn}$ is an essential trace nutrient for plant growth due to its role in various cell functions. It is also important for brain development, wound-healing, bone formation, normal growth, and behavioral response with a dietary limit in humans of $100 \mathrm{ppm}$ [40]. Its deficiency causes diabetes and loss of smell and touch. $\mathrm{Cu}$ is important for normal plant growth but its extreme levels (>100ppm) can cause phytotoxicity [41]. The concentration of $\mathrm{Cu}$ in seed and flower parts exceeded the prescribed WHO limits but its concentration was lower in leaf, stem, and root. Meanwhile, with respect to body weight, the acceptable lower limit of $\mathrm{Cu}$ is $20 \mu \mathrm{g} / \mathrm{mg}$ body weight per day [42]. The deficiency of Mn can cause chlorosis as it is also an essential nutrient for plants [43]. In adult humans, the suitable daily dietary intake of $\mathrm{Mn}$ is $11 \mathrm{mg} /$ day [44]. Mn deficiency causes disorder of bone development in children, which may result in rheumatic arthritis and immunodeficiency disorder in adults $[45,46]$. In case of $\mathrm{Cr}$, the values were higher than the permissible limits as suggested by FAO/WHO. The Cr intake causes toxic effects in humans like irritations of nose, skin rash, lungs cancer, and damage to kidney and liver, whereas its deficiency causes trouble in lipids, protein, and glucose metabolism [47]. For adults, the recommended daily intake of $\mathrm{Cr}$ is $50-200 \mu \mathrm{g} /$ day [48].

\section{Conclusion}

Phytochemicals (tannins, phenols, alkaloids, and flavonoids) were found in all parts of the plant; however, the highest amounts were present in the leaf part of $D$. alba. The presence of these phytochemicals makes the plant antiradically active with the various parts (extracts) of $D$. alba showing antioxidant activity. Methanol showed higher antioxidant activity especially in the leaf extract due to the presence of high concentrations of polyphenolic constituent including flavonoids and tannins. Likewise, the plant contained heavy metals within the WHO/FAO permissible limits except for chromium. From the presence of phytochemicals, antioxidant activity of the plant, and availability of micro and macro elemental nutrients, it could be deduced that $D$. alba could be a prospective addition in pharmaceutical products to improve human health by participating in the antioxidant defense system against production of free radical.

\section{Data Availability}

The data used to support the findings of this study are included within the article. 


\section{Conflicts of Interest}

The authors declare that they have no conflicts of interest.

\section{Acknowledgments}

The authors are grateful to the Deanship of Scientific Research at King Saud University for funding this research through research group no. RG-1440-100.

\section{References}

[1] S. M. K. Rates, "Plants as source of drugs," Toxicon, vol. 39, no. 5, pp. 603-613, 2001.

[2] J. T. Baker, R. P. Borris, B. Carté et al., "Natural product drug discovery and development: new perspectives on international collaboration," Journal of Natural Products, vol. 58, no. 9, pp. 1325-1357, 1995.

[3] S.-T. Fang, X. Liu, N.-N. Kong, S.-J. Liu, and C.-H. Xia, "Two new withanolides from the halophyte Datura stramonium L.," Natural Product Research (Formerly Natural Product Letters), vol. 27, no. 21, pp. 1965-1970, 2013.

[4] P. K. Mukherjee, S. Rai, V. Kumar, K. Mukherjee, P. J. Hylands, and R. C. Hider, "Plants of Indian origin in drug discovery," Expert Opinion on Drug Discovery, vol. 2, no. 5, pp. 633-657, 2007.

[5] H. Bothe and A. Słomka, "Divergent biology of facultative heavy metal plants," Journal of Plant Physiology, vol. 219, pp. 45-61, 2017.

[6] K. Kannan and S. K. Jain, "Oxidative stress and apoptosis," Pathophysiology, vol. 7, no. 3, pp. 153-163, 2000.

[7] M. Innocenti, S. Gallori, C. Giaccherini, F. Ieri, F. F. Vincieri, and N. Mulinacci, "Evaluation of the phenolic content in the aerial parts of different varieties of Cichorium intybus L," Journal of Agricultural and Food Chemistry, vol. 53, no. 16, pp. 6497-6502, 2005.

[8] I. I. Koleva, T. A. van Beek, J. P. H. Linssen, A. de Groot, and L. N. Evstatieva, "Screening of plant extracts for antioxidant activity: a comparative study on three testing methods," Phytochemical Analysis, vol. 13, no. 1, pp. 8-17, 2002.

[9] M. Kampa and E. Castanas, "Human health effects of air pollution," Environmental Pollution, vol. 151, no. 2, pp. 362-367, 2008.

[10] R. A. Floyd and K. Hensley, "Oxidative stress in brain aging: implications for therapeutics of neurodegenerative diseases," Neurobiology of Aging, vol. 23, no. 5, pp. 795-807, 2002.

[11] H. Granda and S. De Pascual-Teresa, "Interaction of polyphenols with other food components as a means for their neurological health benefits," Journal of Agricultural and Food Chemistry, vol. 66, no. 31, pp. 8224-8230, 2018.

[12] S. Bakari, M. Ncir, S. Felhi et al., "Chemical composition and in vitro evaluation of total phenolic, flavonoid, and antioxidant properties of essential oil and solvent extract from the aerial parts of Teucrium polium grown in Tunisia," Food Science and Biotechnology, vol. 24, no. 6, pp. 1943-1949, 2015.

[13] A. M. Weli, S. Al-Salmi, H. Al Hoqani, and M. A. Hossain, "Biological and phytochemical studies of different leaves extracts of Pteropyrum scoparium," Beni-Suef University Journal of Basic and Applied Sciences, vol. 7, no. 4, pp. 481-486, 2018.

[14] V. Ravichandran, S. Vasanthi, S. Shalini, S. A. Ali Shah, and R. Harish, "Green synthesis of silver nanoparticles using Atrocarpus altilis leaf extract and the study of their antimicrobial and antioxidant activity," Materials Letters, vol. 180, pp. 264-267, 2016.

[15] B. Tohidi, M. Rahimmalek, and A. Arzani, "Essential oil composition, total phenolic, flavonoid contents, and antioxidant activity of Thymus species collected from different regions of Iran," Food Chemistry, vol. 220, pp. 153-161, 2017.

[16] S. C. Duda, L. A. Mărghitaş, D. Dezmirean, M. Duda, R. Mărgăoan, and O. Bobiş, "Changes in major bioactive compounds with antioxidant activity of Agastache foeniculum, Lavandula angustifolia, Melissa officinalis and Nepeta cataria: Effect of harvest time and plant species," Industrial Crops and Products, vol. 77, pp. 499-507, 2015.

[17] A. G. Atanasov, B. Waltenberger, E. M. P. Wenzig et al., "Discovery and resupply of pharmacologically active plantderived natural products: a review," Biotechnology Advances, vol. 33, no. 8, pp. 1582-1614, 2015.

[18] I. Ignat, I. Volf, and V. I. Popa, "A critical review of methods for characterisation of polyphenolic compounds in fruits and vegetables," Food Chemistry, vol. 126, no. 4, pp. 1821-1835, 2011.

[19] D. Krishnaiah, T. Devi, A. Bono, and R. Sarbatly, "Studies on phytochemical constituents of six Malaysian medicinal plants," Journal of Medicinal Plants Research, vol. 3, no. 2, pp. 67-72, 2009.

[20] P. Mattila and J. Hellström, "Phenolic acids in potatoes, vegetables, and some of their products," Journal of Food Composition and Analysis, vol. 20, no. 3-4, pp. 152-160, 2007.

[21] N. G. T. Meneses, S. Martins, J. A. Teixeira, and S. I. Mussatto, "Influence of extraction solvents on the recovery of antioxidant phenolic compounds from brewer's spent grains," Separation and Purification Technology, vol. 108, pp. 152-158, 2013.

[22] H. Zhang, L. Jiang, S. Ye, Y. Ye, and F. Ren, "Systematic evaluation of antioxidant capacities of the ethanolic extract of different tissues of jujube (Ziziphus jujuba Mill.) from China," Food and Chemical Toxicology, vol. 48, no. 6, pp. 1461-1465, 2010.

[23] V. E. Tyler, "Phytomedicines in Western Europe," Herbalgram, vol. 30, pp. 24-30, 1994.

[24] O. Oyewole and P. F. Akingbala, "Phytochemical analysis and hypolipidemic properties of jatropha tanjorensis leaf extract," European Journal of Medicinal Plants, vol. 1, no. 4, pp. 180-185, 2011.

[25] M. M. Natić, D. Č. Dabić, A. Papetti et al., "Analysis and characterisation of phytochemicals in mulberry (Morus alba L.) fruits grown in Vojvodina, North Serbia," Food Chemistry, vol. 171, pp. 128-136, 2015.

[26] F. Medini, H. Fellah, R. Ksouri, and C. Abdelly, "Total phenolic, flavonoid and tannin contents and antioxidant and antimicrobial activities of organic extracts of shoots of the plant," Journal of Taibah University for Science, vol. 8, no. 3, pp. 216-224, 2014.

[27] O. I. Oyewole and P. F. Akingbal, "Phytochemical analysis and hypolipidemic properties of jatropha tanjorensis leaf extract," European Journal of Medicinal Plants, vol. 1, no. 4, pp. 180-185, 2011 (Russian).

[28] M. D. Rivero-Pérez, M. L. González-Sanjosé, P. Muñiz, and S. Pérez-Magariño, "Antioxidant profile of red-single variety wines microoxygenated before malolactic fermentation," Food Chemistry, vol. 111, no. 4, pp. 1004-1011, 2008.

[29] T. X. T. Nguyen, M. Amyot, and M. Labrecque, "Differential effects of plant root systems on nickel, copper and silver bioavailability in contaminated soil," Chemosphere, vol. 168, pp. 131-138, 2017. 
[30] T. H. A. Alabri, A. H. S. Al Musalami, M. A. Hossain, A. M. Weli, and Q. Al-Riyami, "Comparative study of phytochemical screening, antioxidant and antimicrobial capacities of fresh and dry leaves crude plant extracts of Datura metel L," Journal of King Saud University - Science, vol. 26, no. 3, pp. 237-243, 2014.

[31] E. Genskowsky, L. A. Puente, J. A. Pérez-Álvarez, J. FernándezLópez, L. A. Muñoz, and M. Viuda-Martos, "Determination of polyphenolic profile, antioxidant activity and antibacterial properties of maqui [Aristotelia chilensis (Molina) Stuntz] a Chilean blackberry," Journal of the Science of Food and Agriculture, vol. 96, no. 12, pp. 4235-4242, 2016.

[32] E. M. Williamson, "Herbal neurotoxicity: an introduction to its occurrence and causes," in Toxicology of Herbal Products, pp. 345-362, Springer, 2017.

[33] N. Bertleff-Zieschang, M. A. Rahim, Y. Ju et al., "Biofunctional metal-phenolic films from dietary flavonoids," Chemical Communications, vol. 53, no. 6, pp. 1068-1071, 2017.

[34] Q. Wang, Y. Li, F. Sun et al., "Tannins improve dough mixing properties through affecting physicochemical and structural properties of wheat gluten proteins," Food Research International, vol. 69, no. 1, pp. 64-71, 2015.

[35] B. L. Sampaio, R. Edrada-Ebel, and F. B. Da Costa, "Effect of the environment on the secondary metabolic profile of Tithonia diversifolia: a model for environmental metabolomics of plants," Scientific Reports, vol. 6, p. 29265, 2016.

[36] Z. K. Abbas, S. Saggu, M. I. Sakeran, N. Zidan, H. Rehman, and A. A. Ansari, "Phytochemical, antioxidant and mineral composition of hydroalcoholic extract of chicory (Cichorium intybus L.) leaves," Saudi Journal of Biological Sciences, vol. 22, no. 3, pp. 322-326, 2014.

[37] N. Huda-Faujan, A. Noriham, A. S. Norrakiah, and A. S. Babji, "Antioxidant activity of plants methanolic extracts containing phenolic compounds," African Journal of Biotechnology, vol. 8, no. 3, pp. 484-489, 2009.

[38] J. P. Dzoyem and J. N. Eloff, "Anti-inflammatory, anticholinesterase and antioxidant activity of leaf extracts of twelve plants used traditionally to alleviate pain and inflammation in South Africa," Journal of Ethnopharmacology, vol. 160, no. 3, pp. 194-201, 2015.

[39] FAO/WHO, Contaminants. In Codex Alimentarius, vol. XVII, FAO/WHO, Codex Alimentarius Commision, Rome, Italy, 1st edition, 1984.

[40] J. Mohmand, S. A. M. A. S. Eqani, M. Fasola et al., "Human exposure to toxic metals via contaminated dust: bio-accumulation trends and their potential risk estimation," Chemosphere, vol. 132, pp. 142-151, 2015.

[41] L. A. Brun, J. Maillet, P. Hinsinger, and M. Pépin, "Evaluation of copper availability to plants in copper-contaminated vineyard soils," Environmental Pollution, vol. 111, no. 2, pp. 293-302, 2001.

[42] D. Waston, Safety of Chemicals in Food, Chemical Contaminants, vol. 109, Ellis, New York, NY, USA, 1993.

[43] A. Lehmann and M. C. Rillig, "Arbuscular mycorrhizal contribution to copper, manganese and iron nutrient concentrations in crops - a meta-analysis," Soil Biology \& Biochemistry, vol. 81, pp. 147-158, 2015.

[44] P. Khankhane, J. G. Varshney, and V. Naidu, "Presence of heavy metals in medicinal weed species grown at contaminated sites," Indian Journal of Weed Science, vol. 44, no. 4, pp. 247-250, 2012.

[45] K. Smith, Manganase and Cobalt in Heavy Metals in Soils, B. J. Alloway, Ed., John Wiley and Sons. Inc, New York, NY, USA, 1990.
[46] S. Yagi, A. E. A. Rahman, G. O. M. ELhassan, and A. M. A. Mohammed, "Elemental analysis of ten sudanese medicinal plants using X-ray fluorescence," Journal of Applied and Industrial Sciences, vol. 1, no. 1, pp. 49-53, 2013.

[47] U. N. Rai, R. D. Tripathi, and N. Kumar, "Bioaccumulation of chromium and toxicity on growth, photosynthetic pigments, photosynthesis, in vivo nitrate reductase activity and protein content in a chlorococcalean green alga Glaucocystis nostochinearum Itzigsohn," Chemosphere, vol. 25, no. 11, pp. 1721$1732,1992$.

[48] I. O. Akinyele and O. S. Shokunbi, "Concentrations of Mn, Fe, $\mathrm{Cu}, \mathrm{Zn}, \mathrm{Cr}, \mathrm{Cd}, \mathrm{Pb}$, Ni in selected Nigerian tubers, legumes and cereals and estimates of the adult daily intakes," Food Chemistry, vol. 173, pp. 702-708, 2015. 

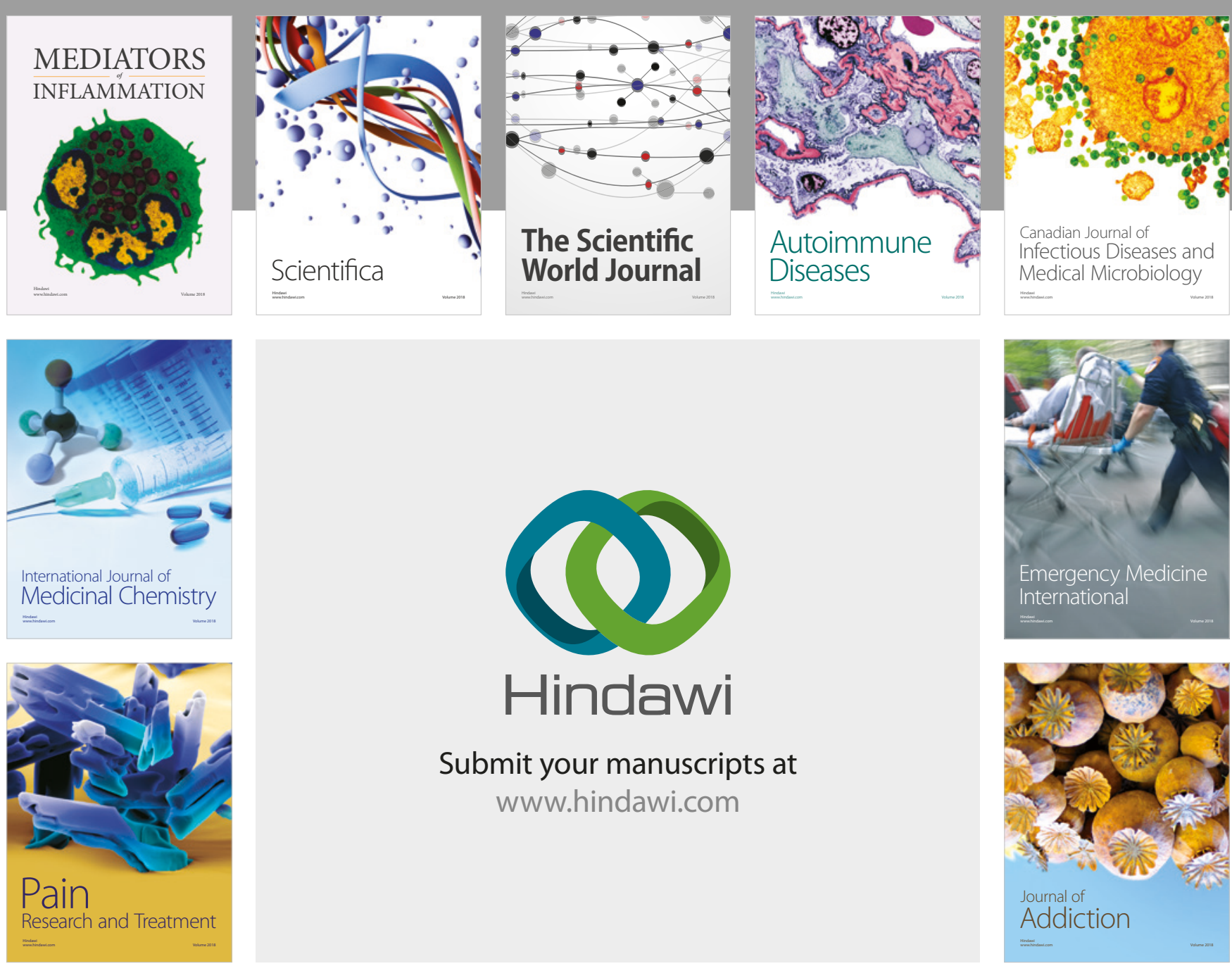

Canadian Journal of
Infectious Diseases and Medical Microbiology

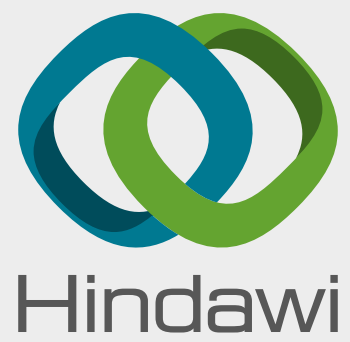

Submit your manuscripts at

www.hindawi.com
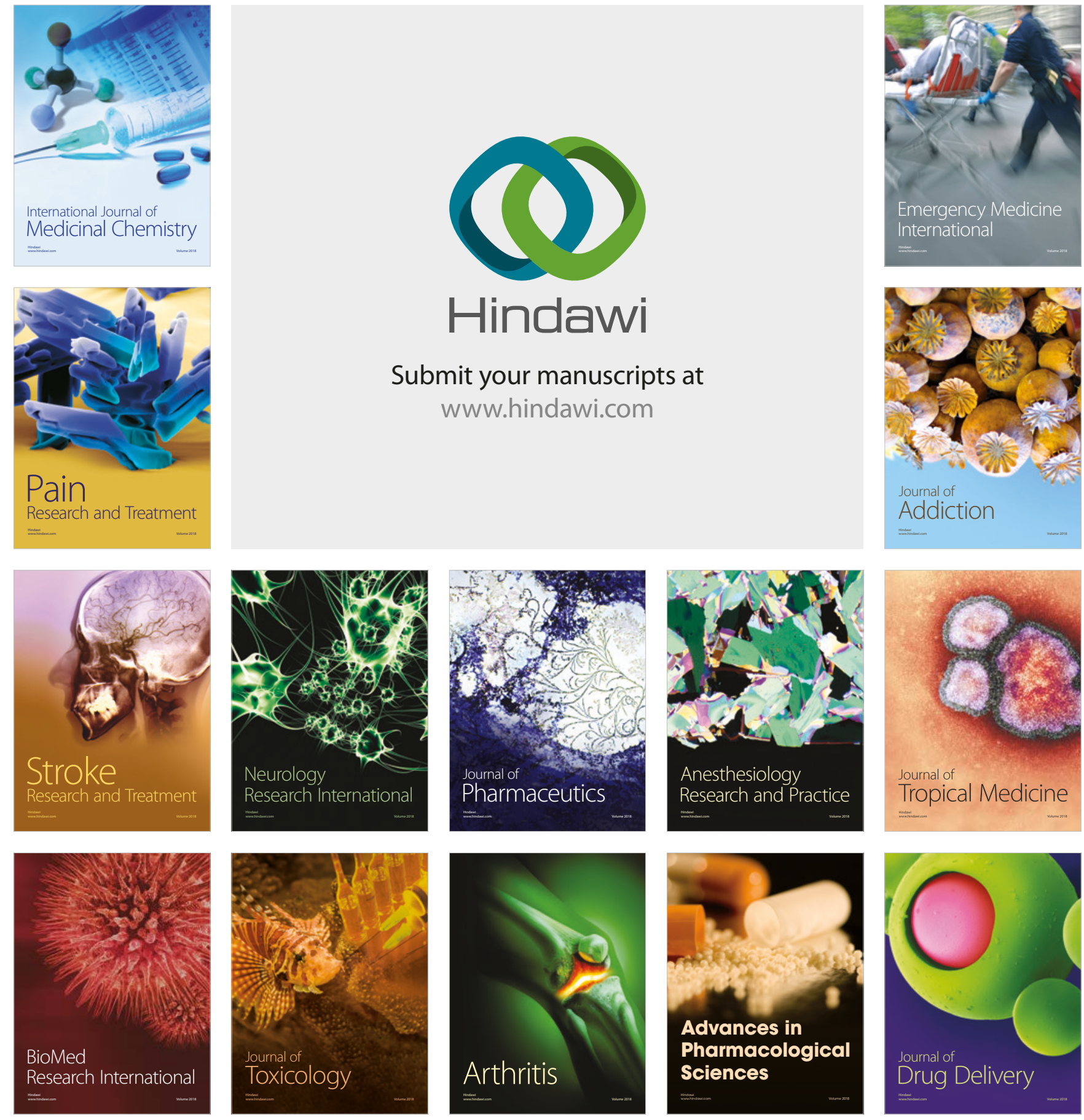